\title{
Diagnostic utility of C-reactive Protein combined with brain natriuretic peptide in acute pulmonary edema: a cross sectional study
}

\author{
Kosaku Komiya ${ }^{1}$, Hiroshi Ishii ${ }^{*}$, Shinji Teramoto², Osamu Takahashi ${ }^{3}$, Nobuoki Eshima ${ }^{4}$, Ou Yamaguchi ${ }^{5}$, \\ Noriyuki Ebi ${ }^{5}$, Junji Murakami ${ }^{6}$, Hidehiko Yamamoto ${ }^{5}$ and Jun-ichi Kadota ${ }^{1}$
}

\begin{abstract}
Introduction Discriminating acute lung injury (ALI) or acute respiratory distress syndrome (ARDS) from cardiogenic pulmonary edema (CPE) using the plasma level of brain natriuretic peptide (BNP) alone remains controversial. The aim of this study was to determine the diagnostic utility of combination measurements of BNP and C-reactive protein (CRP) in critically ill patients with pulmonary edema.

Methods: This was a cross-sectional study. BNP and CRP data from 147 patients who presented to the emergency department due to acute respiratory failure with bilateral pulmonary infiltrates were analyzed.

Results: There were 53 patients with ALI/ARDS, 71 with CPE, and 23 with mixed edema. Median BNP and CRP levels were 202 (interquartile range 95-439) pg/mL and 119 (62-165) $\mathrm{mg} / \mathrm{L}$ in ALI/ARDS, and 691 (416-1,194) $\mathrm{pg} / \mathrm{mL}(\mathrm{p}<$ $0.001)$ and $8(2-42) \mathrm{mg} / \mathrm{L}(\mathrm{p}<0.001)$ in CPE. BNP or CRP alone offered good discriminatory performance (C-statistics 0.831 and 0.887 ), but the combination offered greater one [C-statistics 0.931 ( $p<0.001$ versus BNP) ( $p=0.030$ versus CRP)]. In multiple logistic-regression, BNP and CRP were independent predictors for the diagnosis after adjusting for other variables.
\end{abstract}

Conclusions: Measurement of CRP is useful as well as that of BNP for distinguishing ALI/ARDS from CPE. Furthermore, a combination of BNP and CRP can provide higher accuracy for the diagnosis.

\section{Introduction}

Acute hypoxic respiratory failure due to pulmonary edema is a common reason for visiting the emergency department. The distinction between cardiogenic pulmonary edema (CPE) and acute lung injury (ALI) or acute respiratory distress syndrome (ARDS) is clinically important because the management and the prognosis are different [1]. Hence, possible biomarkers for the differential diagnosis have been investigated using various strategies [2-5]. The most widely used clinical definition of ALI/ARDS is based on the acute onset of respiratory failure, bilateral infiltration on chest radiography, a pulmonary capillary wedge pressure $(\mathrm{PCWP})<18 \mathrm{mmHg}$, or absence of clinical evidence of elevated left atrial pressure [2]. However, clinical estimation of PCWP is notoriously inaccurate [6],

\footnotetext{
* Correspondence: hishii@oita-u.ac.jp

'Department of Internal Medicine 2, Oita University Faculty of Medicine, 1-1 Idaigaoka, Yufu (879-5593), Japan

Full list of author information is available at the end of the article
}

relatively invasive and costly [7], has no clear evidence of benefits $[8,9]$, and may result in potentially adverse clinical outcomes [10]. Moreover, ALI/ARDS with concomitant heart failure complicates the differential diagnosis $[11,12]$. If the respiratory status rapidly improves after the administration of diuretics alone, CPE should be considered, whereas patients who have poor responses to sufficient diuresis should be considered to have non-cardiogenic pulmonary edema. In patients with CPE that was triggered by an airway infection, the respiratory status might not completely improve in response to diuretic treatment, if airway an infection itself influences this status to some degree. Therefore, these patients who cannot undergo invasive examinations, such as bronchoscopy because of poor respiratory conditions, tend to only be diagnosed after the start of treatment [13-16]. However, making an accurate initial diagnosis is still important in the emergency department, and the alternative tools for use in maing a differential diagnosis have been explored using

\section{Biomed Central}


various strategies [17], including the measurement of the alveolar protein concentration [5], as well as the use of chest radiographs $[13,14]$ and echocardiography [18].

Brain natriuretic peptide (BNP) is released from the cardiac ventricles in response to increased cardiac wall tension. Rapid measurement of BNP has been shown to be a sensitive marker of dyspnea due to cardiac causes in the emergency room and intensive care unit settings [19-21]. In critically ill patients with hypoxic respiratory failure due to CPE versus ALI/ARDS, the diagnostic utility of BNP has been extensively investigated $[15,16,22]$, however, the accuracy of discriminating these two disorders by the BNP level alone is still a matter of debate. Several investigators have reported that BNP levels do not accurately discriminate CPE from sepsis [23-25]. Severe sepsis, known as one cause of ALI/ARDS, can increase BNP levels in spite of a normal cardiac function [24]. Therefore, false-positive findings of plasma BNP levels may be found in sepsis-associated ALI/ARDS patients.

On the other hand, C-reactive protein (CRP) is an acute phase protein produced primarily from the liver and is stimulated by the release of cytokines, such as interleukin-6 [26]. CRP is a marker of systematic inflammation that is elevated by a wide variety of diseases $[27,28]$, and is widely-used at numerous emergency departments. The severe inflammatory process of the lung in ALI/ARDS patients occurs in response to various etiologies, including pulmonary or extrapulmonary injury [29]. Although there have been a few reported studies regarding the CRP levels $[27,30]$ in critically ill patients with ALI/ARDS, the differential diagnostic value of CRP for these conditions has not been determined. Furthermore, the utility of using a combination of BNP and CRP has not been examined for the differential diagnosis of ALI/ARDS and CPE.

We therefore assessed the diagnostic utility of measuring the plasma BNP levels combined with CRP levels in patients with hypoxic acute respiratory failure due to CPE versus ALI/ARDS.

\section{Materials and methods}

\section{Setting and patients}

This was a single-center cross-sectional study. The protocol was approved by the institutional review boards of the Aso Iizuka Hospital, and informed consent for participation was obtained from each patient or a surrogate decision maker. The hospital is a large teaching hospital with 1,600 inpatient beds. The emergency physicians routinely measured BNP and CRP levels in the plasma of the emergency outpatients, who met the following criteria: presentation with acute respiratory failure with a $\mathrm{PaO}_{2} /$ fraction of inspired oxygen $\left(\mathrm{FiO}_{2}\right) \leq 300$ [2], bilateral pulmonary infiltrates on chest radiography, and age $\geq 18$ years, between May 2004 and March 2010 at the emergency department. The patients who had the following diagnoses or disease conditions on admission were excluded from this study: previously-detected interstitial pneumonia, severe bronchial asthma (stage III or more severe disease based on the criteria of the Global Initiative for Asthma [31]) or chronic obstructive pulmonary disease (stage III or more severe based on the criteria of the Global Initiative for Chronic Obstructive Lung Disease [32]), distinct acute coronary syndrome, renal failure requiring dialysis, cardiac surgery within 2 months, a preexisting decrease of the left ventricular ejection fraction (LVEF: < $30 \%$ ), malignancies such as lung cancer and lymphoma, intracranial hemorrhage, or cardio-pulmonary arrest in the emergency room.

We designed the study to have a $90 \%$ power $(\beta$-level $=$ 0.01 ) with an $\alpha$-level of 0.05 to show that the AUC of 0.75 for either the CRP or BNP test is significant from the null hypothesis value of 0.5 . A total of 106 subjects (53 subjects in each group) are required [33].

The baseline characteristics recorded at the time of enrollment included the following: patient demographics, past medical history including affectors for CRP producibility (e.g. chronic hepatic failure and receiving corticosteroids), blood pressure, heart rate, body temperature, S3 gallop, $\mathrm{PaO}_{2} / \mathrm{FiO}_{2}$, white blood cell count, renal function, culture results, echocardiographic findings, hemodynamics, Acute Physiology and Chronic Health Evaluation (APACHE) II score, and the need for mechanical ventilation including non-invasive positive pressure ventilation.

\section{Determination of the final diagnosis}

The frequency of RHC examinations for estimating the PCWP has now decreased, because there is no clear evidence of benefit $[8,9]$. We therefore determined the final diagnosis according to the clinical features and responses to treatments. As shown in Table 1, the clinical diagnostic criteria were originally defined to ensure the objectivity of determining the final diagnosis.

First of all, if RHC was examined, the measured value was required for each diagnosis, CPE or ALI/ARDS [2]. Next, the evidence for infection, culture result and/or immunological test was required. This requirement must be cautiously considered. The subjects with ALI/ARDS include non-infectious causes such as pancreatitis or trauma [2], moreover, not all infections are always confirmed by culture results and/or immunological tests. As a result, this condition was set as a requirement for the diagnosis of ALI/ARDS. In contrast, for the diagnosis of $\mathrm{CPE}$ in the present study, this condition was set as an absolute prerequisite in order to rule out the patients with CPE which was triggered by infections as much as 


\begin{tabular}{llrr}
\hline No. & Clinical features & CPE & ALI/ARDS \\
\hline 1 & PCWP in right heart catheterization (if examined), $\mathrm{mmHg}$ & $>18$ & Negative \\
2 & Culture results and/or immunological test for infections & Present & Positive \\
3 & $\mathrm{LVEF}<50 \%$ and/or diastolic dysfunction on echocardiography & Present & Absent \\
4 & Pleural effusion on chest radiographs & Present & Absent \\
5 & $\mathrm{PaO}_{2} / \mathrm{FiO}_{2}>400$ within 3 days after diuresis & &
\end{tabular}

CPE subjects were required No. 1 and No.2, together with at least two features in Nos. 3-5. ALI/ARDS subjects were required No.1, together with at least three features in Nos. 2-5.

The patients who did not meet these diagnostic criteria were categorized as having mixed edema,

ALI: acute lung injury; ARDS: acute respiratory distress syndrome; CPE: cardiogenic pulmonary edema; LVEF: left ventricular ejection fraction; PCWP: pulmonary capillary wedge pressure

possible. Because, CPE triggered by infections could correspond to mixed-type edema. Immunological tests for infections included polymerase chain reaction assays for Pneumocystis jiroveci and acid-fast bacillus, a Cytomegalovirus antigenemia assay, and rapid detection kits for serum Mycoplasma pneumoniae antibody and urinary antigens of Streptococcus pneumoniae and Legionella pneumophila. In additon, heart failure was divided to two types, namely systolic dysfunction or diastolic dysfunction [34], and therefore the condition of No. 3 (Table 1) was stipulated. The presence of pleural effusion on chest radiographs, which was more frequently seen in patients with CPE than those with ALI/ARDS [13,14], and an improvement in the respiratory status with diuresis [15] were also included in these criteria. However, each finding was not absolute for determining the diagnosis. We therefore established multiple options, the CPE subjects were required No. 1 and No. 2, together with at least two features in Nos. 3-5, ALI/ARDS ones were required No.1, together with at least three features in Nos. 2-5. The patients who did not meet these diagnostic criteria were categorized as mixed edema, and thus were excluded from the analyses in this study. These classifications were done by two independent physicians who were blinded to the BNP and CRP data. Of the 147 total enrolled cases, 124 met the above-mentioned criteria, the other 23 cases did not meet the criteria. As a result, 71 patients were diagnosed with CPE, 53 patients with ALI/ARDS, and 23 patients with mixed type pulmonary edema.

\section{Measurements of BNP and CRP}

BNP levels in plasma were measured immediately after the sample collection in the emergency room with a well-validated commercially available immunoassay (Tosoh, Tokyo, Japan) with a detection limit of $4 \mathrm{pg} / \mathrm{mL}$. CRP levels in plasma were measured by a standard sensitive Latex-immunoassay (Denka Seiken, Tokyo, Japan) with a detection limit of $0.1 \mathrm{mg} / \mathrm{L}$. The normal range for this assay is $<10 \mathrm{mg} / \mathrm{L}$. Both values in all patients were measured within 2 hrs after arriving at the emergency department.

\section{Statistical analysis}

Statistical analyses were performed using the PASW statistics 18.0 software package (IBM SPSS, Tokyo, Japan), except for comparison of the receiver operating characteristic (ROC) curve, which was performed using the STATA version 11 software package (Stata, College Station, TX, US). Statistical significance was defined by a $\mathrm{p}$ value $<0.05$ for all analyses. Continuous variables were tested for normality using the Shapiro-Wilk test, and compared using the Student's $t$-test or Mann-Whitney test distribution. The chi-square test was applied for comparing categorical variables, unless one of the categories had fewer than 20 observations, in which case, the Fisher's exact test was applied. For statistically different findings between CPE and ALI/ARDS groups, we used multiple logistic regression analysis to compare the relevant outcomes. Continuous variables were redefined as dichotomous variables using the medians as cut-off values in the study population, excluding mixed edema. The sensitivity, specificity, positive predictive value, negative predictive value, and diagnostic accuracy rates were calculated according to standard definitions. The accuracy of discriminatory performance was compared by the area under ROC curves. The mixed type patients were excluded for all statistical analyses, such as multiple logistic regression and ROC curves with determination of the cut-off levels of BNP and CRP.

\section{Results}

\section{Patient characteristics}

Baseline characteristics and the results of laboratory and clinical examinations of the 147 patients, who were stratified according to their final diagnosis, are shown in Table 2 and 3. The ALI/ARDS subjects included 7 patients with ALI and 46 patients with ARDS. Between the ALI/ARDS and CPE groups, there was no statistical difference in the age, gender, and frequency of a past history of cardiac or pulmonary diseases. In the evaluation of patients who had affectors for CRP producibility, there were three patients (5.7\%) in ALI/ARDS, and seven patients $(9.9 \%)$ in CPE, who had acute hepatic 
Table 2 Baseline patient characteristics at the time of enrollment*

\begin{tabular}{|c|c|c|c|c|}
\hline & ALI/ARDS $(n=53)$ & CPE $(n=71)$ & Mixed $(n=23)$ & $p$ values for ALI/ARDS vs CPE \\
\hline \multicolumn{5}{|l|}{ Patient demographics } \\
\hline age, yrs & $78(69-85)$ & $81(74-89)$ & $81(75-89)$ & 0.083 \\
\hline male gender & $34(64)$ & $35(49)$ & $13(57)$ & 0.100 \\
\hline \multicolumn{5}{|l|}{ History of cardiac disease } \\
\hline chronic heart failure & $18(34)$ & $36(51)$ & $16(70)$ & 0.063 \\
\hline myocardial infarction & $9(17)$ & $18(25)$ & $5(22)$ & 0.264 \\
\hline angina pectoris & $4(8)$ & $7(10)$ & $2(9)$ & 0.654 \\
\hline prior $\mathrm{PCl}$ & $3(6)$ & $7(10)$ & $3(13)$ & 0.606 \\
\hline prior $C A B G$ & $4(8)$ & $5(7)$ & $3(13)$ & 0.915 \\
\hline History of diabetes mellitus & $9(17)$ & $21(30)$ & $7(30)$ & 0.105 \\
\hline \multicolumn{5}{|l|}{ History of pulmonary disease } \\
\hline COPD & $5(9)$ & $2(3)$ & $0(0)$ & 0.114 \\
\hline asthma & $1(2)$ & $1(1)$ & $1(4)$ & 0.834 \\
\hline \multicolumn{5}{|l|}{ Physical examination } \\
\hline systolic blood pressure, $\mathrm{mmHg}$ & $120(100-146)$ & $148(126-170)$ & $126(110-156)$ & $<0.001$ \\
\hline diastolic blood pressure, $\mathrm{mmHg}$ & $67(54-83)$ & $86(70-100)$ & $80(64-89)$ & $<0.001$ \\
\hline heart rate, beats/min & $100(79-113)$ & $108(90-119)$ & $104(90-136)$ & 0.109 \\
\hline body temperature, ${ }^{\circ} \mathrm{F}$ & $98.6(97.0-99.9)$ & $98.1(97.0-98.8)$ & $98.6(97.5-100.8)$ & 0.483 \\
\hline S3 gallop & $2(4)$ & $11(15)$ & $5(22)$ & 0.031 \\
\hline
\end{tabular}

*Data are expressed as the number (\%) or median (interquartile range).

ALI: acute lung injury; ARDS: acute respiratory distress syndrome; CABG: coronary artery bypass graft; COPD: chronic obstructive pulmonary disease; CPE: cardiogenic pulmonary edema; $\mathrm{PCl}$ : percutaneous coronary intervention; PCWP: pulmonary capillary wedge pressure

Table 3 Findings of laboratory and clinical examinations*

\begin{tabular}{|c|c|c|c|c|}
\hline & ALI/ARDS $(n=53)$ & CPE $(n=71)$ & Mixed $(n=23)$ & $p$ value for ALI/ARDS vs CPE \\
\hline \multicolumn{5}{|l|}{ Laboratory findings } \\
\hline WBC count, $\times 1000 / \mu \mathrm{L}$ & $10.4(7.3-12.8)$ & $9.6(7.2-13.4)$ & $9.8(5.9-11.2)$ & 0.587 \\
\hline $\mathrm{CRP}, \mathrm{mg} / \mathrm{L}$ & $119(62-165)$ & $8(2-42)$ & $100(36-184)$ & $<0.001$ \\
\hline BNP, pg/mL & $202(95-439)$ & $691(416-1194)$ & $403(221-1048)$ & $<0.001$ \\
\hline $\mathrm{GFR}, \mathrm{mL} / \mathrm{min}$ & $60.8(28.6-92.9)$ & $46.0(35.9-58.4)$ & $56.2(29.7-86.9)$ & 0.056 \\
\hline $\mathrm{PaO}_{2} / \mathrm{FiO} 2$ & $100(68-147)$ & $111(82-156)$ & $166(9-220)$ & 0.322 \\
\hline Mechanical ventilation & $34(64)$ & $35(49)$ & $9(39)$ & 0.100 \\
\hline APACHE II score & $17(16-19)$ & $17(16-18)$ & $17(16-18)$ & 0.245 \\
\hline Positive culture results & $28(53)$ & $0(0)$ & $0(0)$ & - \\
\hline \multicolumn{5}{|l|}{ Chest radiography } \\
\hline number of patients examined & $53(100)$ & $71(100)$ & $23(100)$ & - \\
\hline infiltrates on two quadrants & $24(45)$ & $38(54)$ & $18(78)$ & 0.468 \\
\hline infiltrates on four quadrants & $28(53)$ & $33(46)$ & $6(26)$ & 0.604 \\
\hline pleural effusion & $43(81)$ & $66(93)$ & $19(83)$ & 0.043 \\
\hline cardiomegaly & $25(47)$ & $39(55)$ & $13(57)$ & 0.500 \\
\hline \multicolumn{5}{|l|}{ Echocardiography } \\
\hline number of patients examined & $50(94)$ & $71(100)$ & $20(87)$ & - \\
\hline LVEF, \% & $60(56-66)$ & $57(45-69)$ & $49(39-65)$ & 0.052 \\
\hline mitral regurgitation $\geq$ grade 2 & $15 / 50(30)$ & $31 / 71(44)$ & $7 / 23(30)$ & 0.182 \\
\hline right ventricular dilation & $13 / 50(26)$ & 29/71 (41) & $8(35)$ & 0.135 \\
\hline \multicolumn{5}{|l|}{ Hemodynamics } \\
\hline number of patients examined & $6(11)$ & $4(6)$ & $3(10)$ & 0.206 \\
\hline PCWP, mmHg & $10(9-13)$ & $32(28-37)$ & $32(26-34)$ & 0.096 \\
\hline
\end{tabular}

*Data are expressed as the number (\%) or median (interquartile range).

ALI: acute lung injury; APACHE: acute physiology and chronic health evaluation; ARDS: acute respiratory distress syndrome; BNP: brain natriuretic peptide; CRP: C-reactive protein; CPE: cardiogenic pulmonary edema; GFR: glomerular filtration rate; LVEF: left ventricular ejection fraction; PCWP: pulmonary capillary wedge pressure 
failure. There were five patients (9.4\%) in ALI/ARDS, and two patients $(2.8 \%)$ in CPE, who received corticosteroids. No significant differences were observed between these prevalence rates $(\mathrm{p}=0.31, \mathrm{p}=0.12$, respectively). The patients with $\mathrm{CPE}$ were more likely to present with high systolic and diastolic blood pressure. All patients with ALI/ARDS had high APACHE II scores, in line with the findings of previous reports $[16,22]$. Echocardiography was performed in $96 \%$ of patients, but RHC was performed in only 13 cases (9\%). The etiology of the 53 patients with ALI/ARDS consisted of 30 with intrapulmonary diseases [including 20 cases of acute pneumonia (38\%) and 10 of aspiration pneumonia (19\%)] and 23 patients with extrapulmonary diseases [including 20 with sepsis (38\%), 1 with burns, 1 with severe pancreatitis, and 1 due to trauma].

BNP in patients with pulmonary edema

As shown in Table 3 and Figure 1A, the initial levels of plasma BNP were significantly different between the patients with CPE and ALI/ARDS. When patients with ALI/ARDS were subclassified into those with sepsis or without sepsis, no significant differences were observed between the median (interquartile range; IQR) BNP levels in patients with sepsis [299 (128-463) $\mathrm{pg} / \mathrm{mL}]$ and those without sepsis $[115(70-417) \mathrm{pg} / \mathrm{mL}]$. The area under the ROC curve (Figure 2) when BNP was used to differentiate CPE from ALI/ARDS was 0.831 ( $\mathrm{p}<0.001)$. A BNP cutoff value of $500 \mathrm{pg} / \mathrm{mL}$ (approximate values as the highest likelihood ratio according to the ROC curves, excluding the mixed type edema) had a sensitivity of $69.0 \%$, a specificity of $83.1 \%$, and an accuracy of 75.0\% for detecting CPE (Table 4).

\section{CRP in patients with pulmonary edema}

The initial levels of plasma CRP in patients with ALI/ ARDS were significantly higher than those with CPE (Table 3 and Figure $1 \mathrm{~B}$ ). The area under the ROC curve (Figure 2) when CRP was used to differentiate CPE from ALI/ARDS was 0.887 ( $<<0.001)$. A CRP cutoff value of $50 \mathrm{mg} / \mathrm{L}$ (approximate values as the highest likelihood ratio according to the ROC curves, excluding the mixed type edema) had a sensitivity of $59.2 \%$, a specificity of $69.8 \%$, and an accuracy of $63.7 \%$ for detecting ALI/ARDS (Table 4).

\section{Predictors of the diagnosis after adjusting for other variables}

By means of multiple logistic-regression analyses, we determined the additional diagnostic power of measurement of BNP and CRP, patients' age, systolic blood pressure, S3 gallop, left ventricular ejection fraction, and the presence of pleural effusion on the chest radiograph. In order to increase the statistical power, continuous

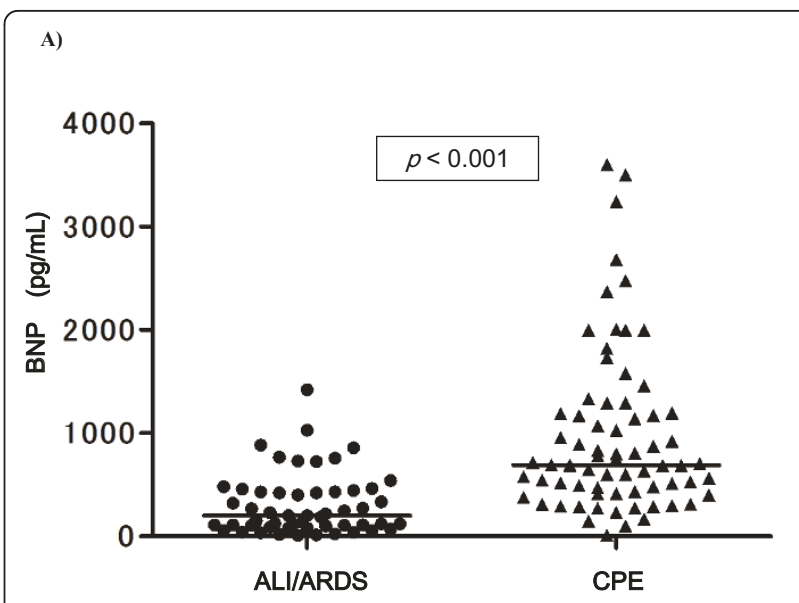

B)

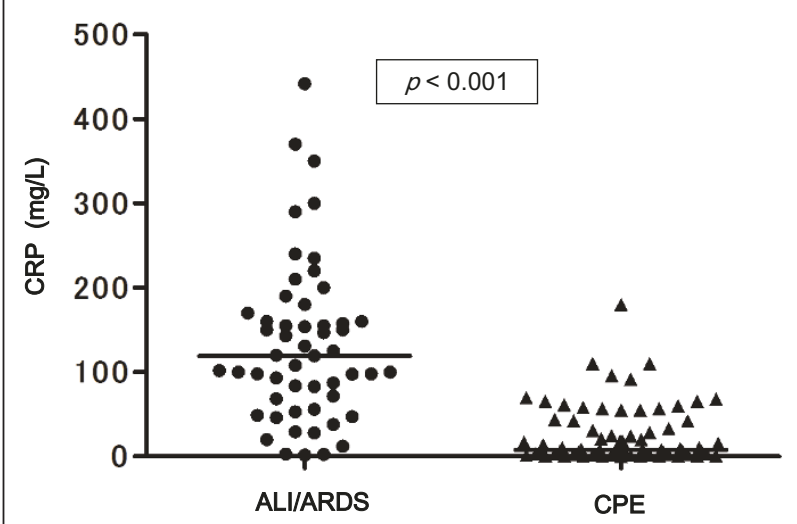

Figure 1 Plasma concentrations of brain natriuretic peptide (BNP) A) and C-reactive protein (CRP) B) in patients with cardiogenic pulmonary edema (CPE) $(n=71)$, or acute lung injury/acute respiratory distress syndrome (ALI/ARDS) with $(n=53)$. The $p$ values show between these subjects. The BNP levels in CPE patients were higher than those in ALI/ARDS patients $(p<0.001)$. The CRP levels in the ALI/ARDS patients were higher than those in the CPE patients $(p<0.001)$.

variables were redefined as dichotomous variables using the following cut-off values: age of 80 years, systolic blood pressure of $135 \mathrm{mmHg}$, left ventricular ejection fraction of $60 \%$ (median of population, respectively), and plasma levels of CRP $50 \mathrm{mg} / \mathrm{L}$ and BNP of $500 \mathrm{pg} / \mathrm{mL}$ (approximate values as the highest likelihood ratio according to the ROC curves, excluding the mixed type edema). This model showed that higher levels of BNP and lower levels of CRP were strong independent predictors of CPE (Table 5).

The value of combination measurements of BNP and CRP in patients with pulmonary edema

As shown in Figure 2, the area under the ROC curve when the combination of BNP and CRP was used to differentiate CPE from ALI/ARDS was 0.931 ( $p<0.001$ ). 


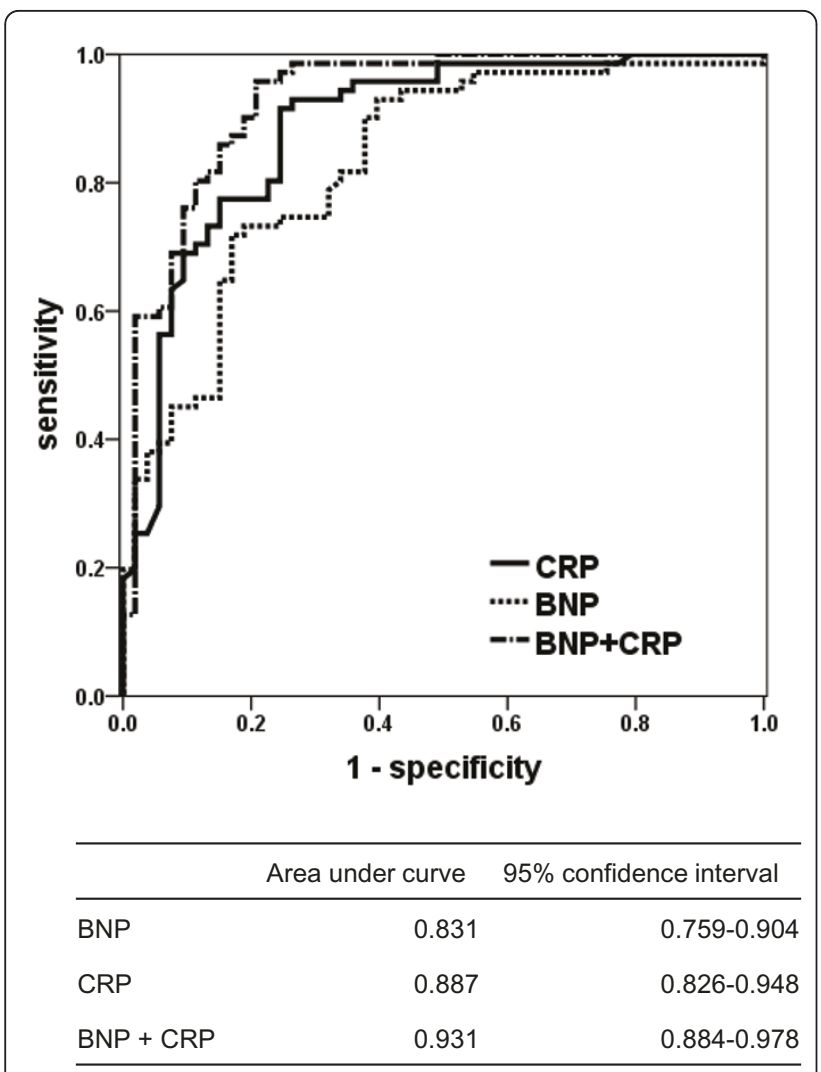

Figure 2 Receiver operating characteristics curve (AUC) analyses of brain natriuretic peptide (BNP), C-reactive protein (CRP), and BNP combined with CRP in discriminating cardiogenic pulmonary edema (CPE) from acute lung injury/acute respiratory distress syndrome (ALI/ARDS), excluding the mixed type of pulmonary edema. CRP levels were converted to the negative values, because lower CRP levels were expected to be more common in CPE patients. $p<0.001$ compared BNP alone with combination BNP and CRP; $p=0.030$ compared CRP alone with BNP and CRP.

There was no significant difference in the area under the ROC curve between BNP alone and CRP alone ( $\mathrm{p}=$ 0.201 ), while the combination of BNP and CRP offered excellent performance compared with BNP alone

Table 4 Performance characteristics of various cut off points of BNP or CRP, excluding mixed type edema

\begin{tabular}{lrrrrr}
\hline Cut-off points & Sensitivity & Specificity & PPV & NPV & Accuracy \\
\hline BNP levels for CPE & & & & & \\
$\geqq 400$ & 80.3 & 66.0 & 76.0 & 71.4 & 74.2 \\
$\geqq 500$ & 69.0 & 83.1 & 84.5 & 66.7 & 75.0 \\
$\geqq 600$ & 60.6 & 84.9 & 84.3 & 61.6 & 71.0 \\
\hline CRP levels for ALI/ARDS & & & & & \\
$\geqq 80$ & 53.5 & 90.6 & 88.4 & 59.3 & 69.4 \\
$\geqq 50$ & 59.2 & 69.8 & 72.4 & 56.1 & 63.7 \\
$\geqq 20$ & 69.0 & 50.9 & 65.3 & 55.1 & 61.3 \\
\hline
\end{tabular}

Cut-off points of BNP (pg/mL), CRP (mg/L), (\%)

ALI: acute lung injury; ARDS: acute respiratory distress syndrome; BNP: brain natriuretic peptide; CRP: C-reactive protein; CPE: cardiogenic pulmonary edema; NPV: negative predictive value; PPV: positive predictive value $(\mathrm{p}<0.001)$ and CRP alone $(\mathrm{p}=0.030)$. There was a moderate correlation between the levels of BNP and CRP $(\rho=-0.414)$.

\section{Discussion}

This study is the first to demonstrate that a combination of the measurement of BNP and CRP levels provides an advantage over measurement of BNP or CRP levels alone for the differential diagnosis of CPE and ALI/ARDS.

The present study demonstrated that BNP had good diagnostic utility for distinguishing CPE from ALI/ ARDS, consistent with the previous reports $[15,22]$. The AUC of BNP measurement for the diagnosis in our study appeared to be higher than those in these previous studies. This might have been due to the timing of the examination. The BNP levels of all patients in our study were measured within $2 \mathrm{hrs}$ after visiting the emergency room, while the median time from the recognition of pulmonary edema to the measurement of BNP was 3 hrs (IQR; 0.5 to 14) in the report by Rana et al [15]. BNP levels generally decrease after treatment for heart failure [35], hence, the high levels and accuracy of our study may be explained by our measurement of BNP levels in most patients before starting treatment.

Several authors also have reported that BNP levels cannot discriminate CPE from sepsis-induced ARDS [23-25], because the plasma BNP level may increase due to myocardial dysfunction or the direct effect of inflammatory mediators produced by myocytes in patients with sepsis, in spite of their normal cardiac function [36]. Our study showed no significant differences in the plasma BNP levels between cases of ALI/ARDS with sepsis and those without sepsis. However, the present study population was relatively small, so it may be difficult to discriminate CPE and ALI/ARDS by using BNP alone if the rate of sepsis is high. Additionally, the BNP levels are also known to be elevated in part as a result of the acute right heart dysfunction that is associated with ARDS $[37,38]$. Increased stretching of the right ventricle and atrium may cause BNP release, independent of left ventricular filling pressure, in patients with ARDS. In the present study, the frequency of right ventricular dilation/hypokinesis when evaluated by the right heart load in echocardiography was not significantly different between CPE and ALI/ARDS patients. However, the evaluation using echocardiography was clinically difficult, and this was one limitation associated with this study. If right heart dysfunction caused by ALI/ARDS influences the plasma BNP levels, a differential diagnosis of CPE versus ALI/ARDS would be extremely difficult using the BNP level alone.

We also demonstrated the usefulness of measuring CRP for distinguishing CPE from ALI/ARDS. Some patients with ALI/ARDS could have severe community 
Table 5 Predictors for distinguishing CPE from ALI/ARDS, excluding the mixed type*

\begin{tabular}{|c|c|c|c|c|c|c|}
\hline \multirow[b]{2}{*}{ Predictors for CPE } & \multicolumn{3}{|c|}{ univariate } & \multicolumn{3}{|c|}{ multivariate } \\
\hline & OR & $95 \% \mathrm{Cl}$ & $p$-value & OR & $95 \% \mathrm{Cl}$ & $p$-value \\
\hline age $>80 y$ & 1.350 & $0.660-2.761$ & 0.411 & 1.125 & $0.370-3.417$ & 0.836 \\
\hline systolic BP > 135 mmHg & 3.148 & $1.496-6.627$ & 0.003 & 3.999 & $1.311-12.198$ & 0.015 \\
\hline S3 gallop sound & 4.032 & $0.845-19.251$ & 0.080 & 9.142 & $0.727-115.032$ & 0.087 \\
\hline $\mathrm{CRP}>50 \mathrm{mg} / \mathrm{L}$ & 0.083 & $0.035-0.196$ & $<0.001$ & 0.106 & $0.035-0.323$ & $<0.001$ \\
\hline $\mathrm{BNP}>500 \mathrm{pg} / \mathrm{mL}$ & 12.50 & $5.057-30.898$ & $<0.001$ & 14.425 & $4.382-47.483$ & $<0.001$ \\
\hline LVEF > 60\% & 0.474 & $0.223-1.006$ & 0.052 & 0.799 & $0.258-2.476$ & 0.697 \\
\hline Pleural effusion on chest radiograph & 2.805 & $0.881-8.932$ & 0.081 & 5.293 & $0.791-35.434$ & 0.086 \\
\hline
\end{tabular}

*Results of multiple logistic regression analysis.

ALI: acute lung injury; ARDS: acute respiratory distress syndrome; BNP: brain natriuretic peptide; BP: blood pressure; CRP: C-reactive protein; CPE: cardiogenic pulmonary edema; LVEF: left ventricular ejection fraction

acquired pneumonia (CAP) cases with a score of 4 or 5 based on the CURB65 severity score for CAP [39]. Recent studies demonstrated that CRP is an independent marker of the severity of CAP $[40,41]$. Therefore, the CRP levels in patients with ALI/ARDS, including severe pneumonia, may be useful for distinguishing these cases from patients with CPE. Although the individual measurements of BNP or CRP are effective for differentiating ALI/ARDS from CPE, we found the combination measurement of BNP and CRP to provide better results compared with measuring either BNP or CRP alone. Because the BNP level can increase in patients with sepsis, our results suggest that measuring both CRP and BNP can eliminate this drawback to the measurement of BNP alone. Therefore, this combination measurement will help physicians determine a differential diagnosis for critically ill patients with pulmonary edema, even if the patients are suspected to have sepsis or acute cor pulmonale induced by ALI/ARDS. As the value of RHC, echocardiography, and the measurement of BNP alone for the differential diagnosis is still controversial, our results suggest that a combination of the measurements of BNP and CRP may therefore be an effective additional or alternative, non-invasive, and inexpensive diagnostic strategy.

This study has several limitations. First, this study validated clinical diagnoses, because an objective "gold standard" method for diagnosis of ALI/ARDS is absent. Although we performed a multiple logistic regression analysis and showed that BNP was an independent predictor, the possibility of collinearity between each surrogate feature (such as PCWP or LVEF as listed in the clinical diagnostic criteria) and BNP cannot be completely ruled out. Second, there was a relatively high number of mixed-type cases of pulmonary edema, and these cases were excluded for the statistical analyses. Finally, this study was limited to a still small sample size at a single center.

In clinical practice, we occasionally provide treatment concurrently targeting both CPE and ALI/ARDS for critical patients. This is important in several cases, however, we must continue to challenge the differential diagnosis of pulmonary edema in order to provide an optimal treatment. Better diagnoses will lead to better treatment and thereby contribute to better patient outcomes.

\section{Conclusions}

This is the first report evaluating the utility of measuring both CRP and BNP in plasma to provide a differential diagnosis in patients with pulmonary edema. Our results indicate that measurement of CRP could be useful as well as BNP for discriminating ALI/ARDS from CPE. In addition, the evaluation of the combination of CRP and BNP can provide an even higher accuracy for the diagnosis. It is hoped that a large multi-center survey including cases of sepsis-induced ARDS can be accomplished in the near future.

\section{List of abbreviations}

ALI: acute lung injury; APACHE: acute physiology and chronic health evaluation; ARDS: acute respiratory distress syndrome; AUC: area under the curve; BNP: brain natriuretic peptide; Cl: confidence interval; COPD: chronic obstructive pulmonary disease; CPE: cardiogenic pulmonary edema; LVEF: left ventricular ejection fraction; IQR: interquartile range; OR: odds ratio; PCWP: pulmonary capillary wedge pressure; RHC: right heart catheterization; ROC: receiver operating characteristic.

\section{Acknowledgements}

The authors thank Drs. T Kuroiwa, T Fukuya, and S Oguri in the Division of Radiology of Aso lizuka Hospital for their pertinent advice and expertise.

\section{Author details}

'Department of Internal Medicine 2, Oita University Faculty of Medicine, 1-1 Idaigaoka, Yufu (879-5593), Japan. '2Department of Respiratory Medicine, Graduate School of Comprehensive Human Sciences, University of Tsukuba, Hitachinaka Education and Research Center, 20-1 Ishikawa, Hitachinaka (3170077), Japan. ${ }^{3}$ Center for Clinical Epidemiology, St. Luke's Life Science Institute, 10-1 Akashi-machi, Chuo (104-0044), Japan. ${ }^{4}$ Department of Biostatistics, Oita University Faculty of Medicine, 1-1 Idaigaoka, Yufu (8795593), Japan. ${ }^{5}$ Departments of Respiratory Medicine, Aso lizuka Hospital, 3-83 Yoshio-machi, lizuka (820-0018), Japan. ${ }^{6}$ Department of Radiology, Aso lizuka Hospital, 3-83 Yoshio-machi, lizuka (820-0018), Japan. 


\section{Authors' contributions}

$\mathrm{KK}, \mathrm{HI}$ and $\mathrm{ST}$ designed this study and drafted the manuscript. OT and NE participated in the design of the study and performed the statistical analysis. $\mathrm{OY}, \mathrm{NE}, \mathrm{JM}, \mathrm{YH}$ and JK conceived of the study, and participated in its design and coordination and helped to draft the manuscript. All authors read and approved the final manuscript.

\section{Competing interests}

All of the authors explicitly declare that there are no conflicts of interest in connection with this article.

Received: 11 March 2011 Accepted: 22 June 2011

Published: 22 June 2011

\section{References}

1. Brower RG, Ware LB, Berthiaume Y, Matthay MA: Treatment of ARDS. Chest 2001, 120:1347-1367.

2. Bernard GR, Artigas A, Brigham KL, Carlet J, Falke K, Hudson L, Lamy M, Legall JR, Morris A, Spragg R: The American-European Consensus Conference on ARDS. Definitions, mechanisms, relevant outcomes, and clinical trial coordination. Am J Respir Crit Care Med 1994, 149:818-824.

3. Sloane PJ, Gee MH, Gottlieb JE, Albertine KH, Peters SP, Burns JR, Machiedo G, Fish JE: A multicenter registry of patients with acute respiratory distress syndrome. Physiology and outcome. Am Rev Respir Dis 1992, 146:419-426.

4. Monnet X, Anguel N, Osman D, Hamzaoui O, Richard C, Teboul JL: Assessing pulmonary permeability by transpulmonary thermodilution allows differentiation of hydrostatic pulmonary edema from ALI/ARDS. Intensive Care Med 2007, 33:448-453.

5. Fein A, Grossman RF, Jones JG, Overland E, Pitts L, Murray JF, Staub NC: The value of edema fluid protein measurement in patients with pulmonary edema. Am J Med 1979, 67:32-38.

6. Eisenberg PR, Jaffe AS, Schuster DP: Clinical evaluation compared to pulmonary artery catheterization in the hemodynamic assessment of critically ill patients. Crit Care Med 1984, 12:549-553.

7. Mermel LA, Maki DG: Infectious complications of Swan-Ganz pulmonary artery catheters. Pathogenesis, epidemiology, prevention, and management. Am J Respir Crit Care Med 1994, 149:1020-1036.

8. Sandham JD, Hull RD, Brant RF, Knox L, Pineo GF, Doig CJ, Laporta DP, Viner S, Passerini L, Devitt H, Kirby A, Jacka M, Canadian Critical Care Clinical Trials Group: A randomized, controlled trial of the use of pulmonary-artery catheters in high-risk surgical patients. N Engl J Med 2003, 348:5-14.

9. Harvey S, Harrison DA, Singer M, Ashcroft J, Jones CM, Elbourne D, Brampton W, Williams D, Young D, Rowan K, collaboration PA-Ms: Assessment of the clinical effectiveness of pulmonary artery catheters in management of patients in intensive care (PAC-Man): a randomised controlled trial. Lancet 2005, 366:472-477.

10. Connors AF Jr, Speroff T, Dawson NV, Thomas C, Harrell FE Jr, Wagner D, Desbiens N, Goldman L, Wu AW, Califf RM, Fulkerson WJ, Vidaillet H Jr, Broste S, Bellamy P, Lynn J, Knaus WA: The effectiveness of right heart catheterization in the initial care of critically ill patients. SUPPORT Investigators. JAMA 1996, 276:889-897.

11. Montgomery AB, Stager MA, Carrico CJ, Hudson LD: Causes of mortality in patients with the adult respiratory distress syndrome. Am Rev Respir Dis 1985, 132:485-489

12. Zimmerman GA, Morris AH, Cengiz M: Cardiovascular alterations in the adult respiratory distress syndrome. Am J Med 1982, 73:25-34.

13. Milne EN, Pistolesi M, Miniati M, Giuntini C: The radiologic distinction of cardiogenic and noncardiogenic edema. AJR Am J Roentgenol 1985, 144:879-894.

14. Aberle DR, Wiener-Kronish JP, Webb WR, Matthay MA: Hydrostatic versus increased permeability pulmonary edema: diagnosis based on radiographic criteria in critically ill patients. Radiology 1988, 168:73-79.

15. Rana R, Vlahakis NE, Daniels CE, Jaffe AS, Klee GG, Hubmayr RD, Gajic O: Btype natriuretic peptide in the assessment of acute lung injury and cardiogenic pulmonary edema. Crit Care Med 2006, 34:1941-1946.

16. Levitt JE, Vinayak AG, Gehlbach BK, PohIman A, Van Cleve W, Hall JB, Kress JP: Diagnostic utility of B-type natriuretic peptide in critically ill patients with pulmonary edema: a prospective cohort study. Crit Care 2008, 12:R3.
17. Ware LB, Matthay MA: Clinical practice. Acute pulmonary edema. N Engl J Med 2005, 353:2788-2796.

18. Nagueh SF, Kopelen HA, Zoghbi WA: Feasibility and accuracy of Doppler echocardiographic estimation of pulmonary artery occlusive pressure in the intensive care unit. Am J Cardiol 1995, 75:1256-1262.

19. Mueller C, Scholer A, Laule-Kilian K, Martina B, Schindler C, Buser P, Pfisterer M, Perruchoud AP: Use of B-type natriuretic peptide in the evaluation and management of acute dyspnea. N Engl J Med 2004, 350:647-654.

20. Davis M, Espiner E, Richards G, Billings J, Town I, Neill A, Drennan C, Richards M, Turner J, Yandle T: Plasma brain natriuretic peptide in assessment of acute dyspnoea. Lancet 1994, 343:440-444.

21. Maisel AS, Krishnaswamy P, Nowak RM, McCord J, Hollander JE, Duc P, Omland T, Storrow AB, Abraham WT, Wu AH, Clopton P, Steg PG, Westheim A, Knudsen CW, Perez A, Kazanegra R, Herrmann HC, McCullough PA: Breathing Not Properly Multinational Study, Investigators: Rapid measurement of B-type natriuretic peptide in the emergency diagnosis of heart failure. N Engl J Med 2002, 347:161-167.

22. Karmpaliotis D, Kirtane AJ, Ruisi CP, Polonsky T, Malhotra A, Talmor D, Kosmidou I, Jarolim P, de Lemos JA, Sabatine MS, Gibson CM, Morrow D: Diagnostic and prognostic utility of brain natriuretic Peptide in subjects admitted to the ICU with hypoxic respiratory failure due to noncardiogenic and cardiogenic pulmonary edema. Chest 2007, 131:964-971

23. Januzzi JL, Morss A, Tung R, Pino R, Fifer MA, Thompson BT, LeeLewandrowski E: Natriuretic peptide testing for the evaluation of critically ill patients with shock in the intensive care unit: a prospective cohort study. Crit Care 2006, 10:R37.

24. Rudiger A, Gasser S, Fischler M, Hornemann T, von Eckardstein A, Maggiorini M: Comparable increase of B-type natriuretic peptide and amino-terminal pro-B-type natriuretic peptide levels in patients with severe sepsis, septic shock, and acute heart failure. Crit Care Med 2006, 34:2140-2144.

25. Tung RH, Garcia C, Morss AM, Pino RM, Fifer MA, Thompson BT, Lewandrowski K, Lee-Lewandrowski E, Januzzi JL: Utility of B-type natriuretic peptide for the evaluation of intensive care unit shock. Crit Care Med 2004, 32:1643-1647.

26. Okamura JM, Miyagi JM, Terada K, Hokama Y: Potential clinical applications of C-reactive protein. J Clin Lab Anal 1990, 4:231-235.

27. Lobo SM, Lobo FR, Bota DP, Lopes-Ferreira F, Soliman HM, Melot C, Vincent JL: C-reactive protein levels correlate with mortality and organ failure in critically ill patients. Chest 2003, 123:2043-2049.

28. Smith RP, Lipworth BJ, Cree IA, Spiers EM, Winter JH: C-reactive protein. A clinical marker in community-acquired pneumonia. Chest 1995, 108:1288-1291.

29. Ware LB: Pathophysiology of acute lung injury and the acute respiratory distress syndrome. Semin Respir Crit Care Med 2006, 27:337-349.

30. Bajwa EK, Khan UA, Januzzi JL, Gong MN, Thompson BT, Christiani DC: Plasma C-reactive protein levels are associated with improved outcome in ARDS. Chest 2009, 136:471-480.

31. Global Initiative for Asthma: Global strategy for asthma management and prevention. 2008 [http://www.ginasthma.com], Accessed December 2, 2008.

32. Global Initiative for Chronic Obstructive Lung Disease: Global Strategy for the Diagnosis, Management, and Prevention of Chronic Obstructive Pulmonary Disease. 2010 [http://www.goldcopd.com/GuidelinesResources. asp?|1=2\&|2=0], Accessed April 23, 2010.

33. Hanley JA, MCNeil BJ: The meaning and use of the area under a receiver operating characteristic (ROC) curve. Radiology 1982, 143:29-36.

34. Grossman W: Diastolic dysfunction in congestive heart failure. N Engl J Med 1991, 325:1557-1564.

35. Gackowski A, Isnard R, Golmard JL, Pousset F, Carayon A, Montalescot G, Hulot JS, Thomas D, Piwowarska W, Komajda M: Comparison of echocardiography and plasma B-type natriuretic peptide for monitoring the response to treatment in acute heart failure. Eur Heart J 2004, 25:1788-1796.

36. Charpentier J, Luyt CE, Fulla Y, Vinsonneau C, Cariou A, Grabar S, Dhainaut JF, Mira JP, Chiche JD: Brain natriuretic peptide: A marker of myocardial dysfunction and prognosis during severe sepsis. Crit Care Med 2004, 32:660-665. 
37. Vieillard-Baron A, Page B, Augarde R, Prin S, Qanadli S, Beauchet A, Dubourg $\mathrm{O}$, Jardin F: Acute cor pulmonale in massive pulmonary embolism: incidence, echocardiographic pattern, clinical implications and recovery rate. Intensive Care Med 2001, 27:1481-1486.

38. Nagaya N, Nishikimi T, Okano Y, Uematsu M, Satoh T, Kyotani S, Kuribayashi S, Hamada S, Kakishita M, Nakanishi N, Takamiya M, Kunieda T, Matsuo H, Kangawa K: Plasma brain natriuretic peptide levels increase in proportion to the extent of right ventricular dysfunction in pulmonary hypertension. J Am Coll Cardiol 1998, 31:202-208.

39. Lim WS, van der Eerden MM, Laing R, Boersma WG, Karalus N, Town Gl, Lewis SA, Macfarlane JT: Defining community acquired pneumonia severity on presentation to hospital: an international derivation and validation study. Thorax 2003, 58:377-382.

40. Chalmers JD, Singanayagam A, Hill AT: C-reactive protein is an independent predictor of severity in community-acquired pneumonia. Am J Med 2008, 121:219-225.

41. Almirall J, Bolibar I, Toran P, Pera G, Boquet X, Balanzo X, Sauca G, Community-Acquired Pneumonia Maresme Study G: Contribution of Creactive protein to the diagnosis and assessment of severity of community-acquired pneumonia. Chest 2004, 125:1335-1342.

doi:10.1186/1465-9921-12-83

Cite this article as: Komiya et al:: Diagnostic utility of C-reactive Protein combined with brain natriuretic peptide in acute pulmonary edema: a cross sectional study. Respiratory Research 2011 12:83.

\section{Submit your next manuscript to BioMed Central and take full advantage of:}

- Convenient online submission

- Thorough peer review

- No space constraints or color figure charges

- Immediate publication on acceptance

- Inclusion in PubMed, CAS, Scopus and Google Scholar

- Research which is freely available for redistribution

Submit your manuscript at www.biomedcentral.com/submit 